\title{
ELECTRONYSTAGMOGRAPHY VERSUS VIDEONYSTAGMOGRAPHY IN DIAGNOSIS OF VERTIGO
}

\author{
PIOTR PIETKIEWICZ1 ${ }^{\text {, RENATA PEPAŚ }}{ }^{1}$, WIESŁAW J. SUŁKOWSKI ${ }^{1,2}$, HANNA ZIELIŃSKA-BLIŹNIEWSKA ${ }^{1}$, \\ and JUREK OLSZEWSKI ${ }^{1}$
}

${ }^{1}$ Medical University of Łódź, Łódź, Poland

Department of Otolaryngology and Laryngological Oncology

${ }^{2}$ Nofer Institute of Occupational Medicine, Łódź, Poland

Department of Occupational Diseases and Toxicology

\begin{abstract}
Objectives: Vertigo is a very common symptom mainly caused by the lesion of vestibular system (peripheral or central) and often accompanied by some work-related diseases and occupational intoxications. The aim of this study was to assess the value of electronystagmography (ENG) and videonystagmography (VNG) for diagnosing vertigo of various origin. Materials and Methods: The study included four groups, 25 subjects each, of patients suffering from vestibular disorders of peripheral, central and mixed origin versus healthy controls. All were examined by means of ENG and VNG, using the bithermal caloric test with $30^{\circ} \mathrm{C}$ and $44^{\circ} \mathrm{C}$ air irrigations of the ears. The findings (frequency of induced nystagmus FRQ, its slow phase velocity SPV, canal paresis CP, directional preponderance DP, vestibular excitability VE) were analysed and compared. Results: In all patients with vertigo due to vestibular neuritis, barotrauma and kinetosis, significant $\mathrm{CP}$, the important sign of peripheral site of vestibular lesion was identified both in ENG and VNG. None of the patients with central origin disorders showed CP in VNG; in the majority of cases DP was observed. However, in ENG we found CP in 5 patients with central origin disorders. There were no essential differences between ENG and VNG in measurements of FRQ and SPV except for higher values in VNG in controls and patients with mixed vertigo. Conclusions: The results suggest that the VNG should be recommended in preference as the valuable method to assess vertigo and to discriminate between the peripheral and the central vestibular lesions.
\end{abstract}

Key words:

Peripheral, Central and mixed vertigo, Occupational Disorders, ENG, VNG

\section{INTRODUCTION}

Vertigo, defined as an unpleasant illusion of one's own body movement, is one of the most complicated morbid symptoms. It is difficult to identify, practically impossible to measure and not easy to treat. The symptom may result from a disease due to various causes (with both the peripheral or central vestibular or retrovestibular etiology), differing in severity (from minor to very severe) and prevalence, while its early diagnosis can be of immense importance for further fate of the affected person [1,2]. Vertigo may also reflect functional disorders without underlying somatic damage.

The causes of vestibular dysfunction accompanied by vertigo and/or balance disorders include occupational exposure to known ototoxic chemicals, such as toluene, xylene, styrene, n-hexane, trichloroethylene and their mixtures, carbon disulfide, carbon monoxide [3]. Besides, vertigo appears very often also in some work-related diseases, as for example whole body vibrations syndrome, otic barotrauma, decompression sickness, kinetosis [4]. Vertigo

Received: September 27, 2011. Accepted: October 20, 2011.

Address reprint requests to J. Olszewski, Department of Otolaryngology and Laryngological Oncology, Medical University of Łódź, Żeromskiego 113, $90-549$ Łódź, Poland (e-mail: jurek.olszewski@umed.lodz.pl). 
is one of the most frequent and major outpatient clinic complaints, and its prevalence is estimated to range between 17-33\% [5-9] increasing in patients older than 50, who may be affected by presbyastasis [4-7,9-13]. Hence, a great need for precise and effective diagnostics is undoubted and urgent.

Fortunately, the subjective feeling of vertigo may be objectively verified by measurement of nystagmus, i.e., spontaneous or induced (e.g., by caloric or rotatory stimuli) two-phase slow movement of the eyes to one direction followed by rapid recoil to the other direction, which enables the qualitative and quantitative assessment of vestibular system lesion.

Currently, two main modern tools are available for such an assessment: electronystagmography (ENG) and videonystagmography (VNG). ENG, based on the corneal retinal potential measurement using electrodes, records and displays on-line the changing voltages resulting from eye movements occurring throughout various tests. The next tool, VNG, records and displays the eye movements watched directly by infra-red video goggles with minicamera. The aim of the study was to evaluate the diagnostic usefulness of both methods and to analyze the differences and similarities in their results obtained in selected vestibular tests.

\section{MATERIAL AND METHODS}

The study comprised 100 subjects, including patients hospitalized at the Department of Otolaryngology and Laryngological Oncology, Medical University Teaching Hospital - Central Veterans' Hospital in Łódź, due to vertigo, and healthy students of the Military Medical Faculty and the Faculty of Physiotherapy, Medical University in Łódź, who were divided into 4 groups:

- I - 25 patients (10 women, 15 men) with the disorders of central origin (mean age 53.68 \pm 14.97 years) mostly cases of carotid-vertebral ischemic syndrome, brain concussion, multiple sclerosis;
- $\quad$ II - 25 patients ( 16 women, 9 men) with the disorders of peripheral origin (mean age $55.36 \pm 14.42$ years) among other the cases of vestibular neuritis, otic barotrauma, kinetosis;

- III - 25 patients (20 women, 5 men) with mixed disorders (mean age $51.60 \pm 14.46$ years) - comprising the cases of vertebral artery hypoplasia, vertebro-basilar insufficiency;

- IV - 25 healthy students (11 women, 14 men) aged 22-26 years (mean 23.72 \pm 1.14 ) without complaints of vertigo and/or balance disorders.

The criteria for inclusion into individual groups were: medical history, laryngological and otoneurological examinations including: cerebellar and static-dynamic tests. Additionally, when required, laboratory tests were performed (blood cell count, glucose level, cholesterol level). Imaging investigations included: vertebrobasilar ultrasonography (USG-D) or angio-CT, RTG or computed tomography of cervical spine and cerebral CT or MRI.

All subjects were examined with ENG (including calibration, registration of possible spontaneous nystagmus with open/closed eyes, the alternate binaural bithermal caloric test with cool $30^{\circ} \mathrm{C}$ and warm $44^{\circ} \mathrm{C}$ air irrigations) [8] and then, after 1- or 2-day interval for the patients groups and 7-day interval for the controls, the same tests were performed with the use of VNG. Computerized systems PC-ENG and VNG Ulmer - Synapsis were applied for the automatic analysis of the recordings.

The following parameters, i.e., presence of spontaneous nystagmus, values of frequency of induced nystagmus (FRQ), its slow phase angular velocity (SPV) and vestibular excitability (VE), and the scores of canal paresis $(\mathrm{CP})$ and directional preponderance of nystagmus (DP) were considered in the analysis. For the purpose of this report, $\pm 14 \%, \pm 20 \%$, of CP, DP for ENG and $<15 \%,<11 \%, 6-80 \%$ of CP, DP, VE for $\mathrm{VNG}$, respectively, were selected as the normal 


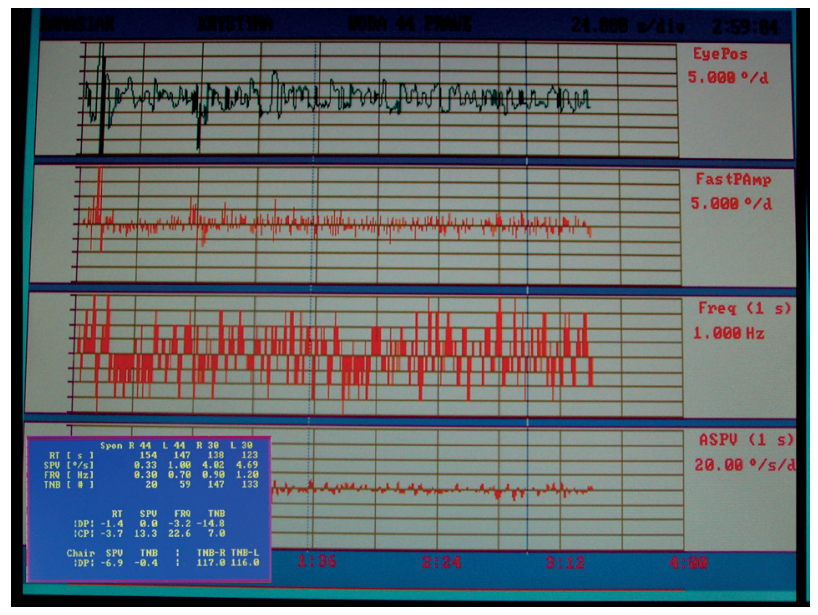

Fig. 1. Electronystagmography - caloric test recording after irrigation of the air at $44^{\circ} \mathrm{C}$ to the right ear in the healthy student (group IV)

values; this is close to the respective values specified by the producers of the equipment. The normal range of caloric responses is diagnostically important to define an abnormally low or a hyperactive response as well as pathological CP or DP.

Figures 1 and 2 illustrate the records of bithermal caloric test with use of ENG and VNG.

Wilcoxon pair sequence test was administered in statistical evaluation.

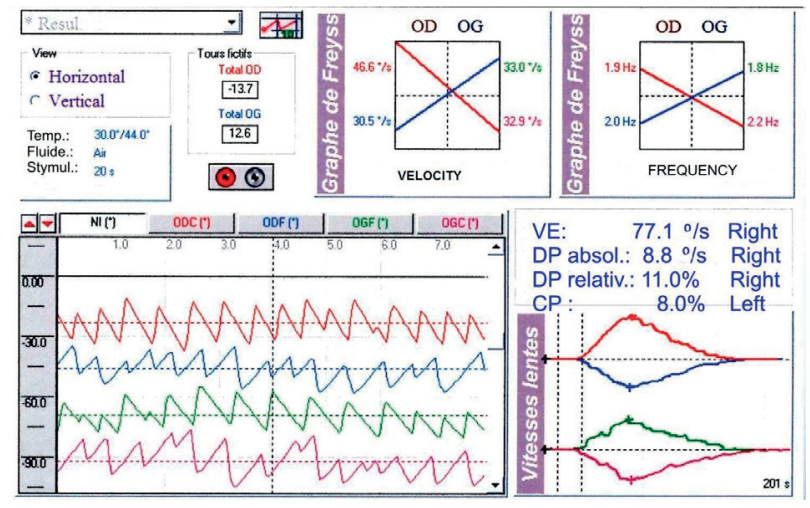

Fig. 2. Videonystagmography - caloric test recording after binaural bithermal stimulation in the healthy student (group IV). Graphic representation of findings (qualitative assessment): in upper diagrams - "butterfly" graphs, left lower diagram - post-caloric two-phase nystagmus ("tree"), right lower diagram - "radish" graphs

\section{RESULTS}

The findings reported in ENG and VNG testing were assessed and compared in individual groups of the subjects. In group I (vertigo of central origin) the values of DP exceeding normal range were observed in ENG and VNG examinations as follows: in 11 cases (44\%) simultaneously in VNG and ENG, whereas in 5 patients (20\%) only in ENG and in 6 patients (24\%) only in VNG. None of the patients showed abnormal CP score in VNG; however, in ENG examination the normal limit values were exceeded in 5 patients (20\%). The mean VE was $7.33 \% \pm 7.01$ : in 12 subjects (48\%) on the right side and the mean was $7.13^{\circ} / \mathrm{s} \pm 3.52$ and in 13 subjects $(52 \%)$ on the left side with the mean $8.29^{\circ} / \mathrm{s} \pm 9.28$. The FRQ mean values were observed to be higher in VNG vs. ENG examination in three cases (L44, R30, L30), whereas in one case (R30) they were lower in VNG than in ENG (Figure 3a); the differences were not statistically significant. To the contrary, a statistically significant difference of the SPV mean value was detected in one case - L30 ( $p<0.05)$; in that case, significantly lower mean values were obtained in ENG examination, i.e. $4.98 \pm 4.48^{\circ} / \mathrm{s}$. In the half of the investigated patients of group I, ENG scores did not exceed $3.35 \%$, whereas the VNG mean values were $6.28^{\circ} / \mathrm{s} \pm 4.48$ and in half of the patients the results higher than $4.40 \%$ s were obtained (Figure 3b).

In group II patients (vertigo of peripheral origin) the values of DP exceeding the normal range, both in ENG and VNG examinations, were found only in 3 patients $(13 \%)$.

However, $\mathrm{CP}$ exceeding the normal range was observed in all investigated patients both in ENG and VNG. The mean of VE was $8.14^{\circ} / \mathrm{s} \pm 5.18$ : in 15 patients $(60 \%)$ on the right side, mean value $6.97 \% \mathrm{~s} \pm 5.39$ and in $10(40 \%)$ on the left side, mean value $9.91 \% \pm 4.55$. The mean values of FRQ were higher in ENG than in VNG examination (Figure 4a), but the differences were not statistically significant. No statistically significant difference was also 

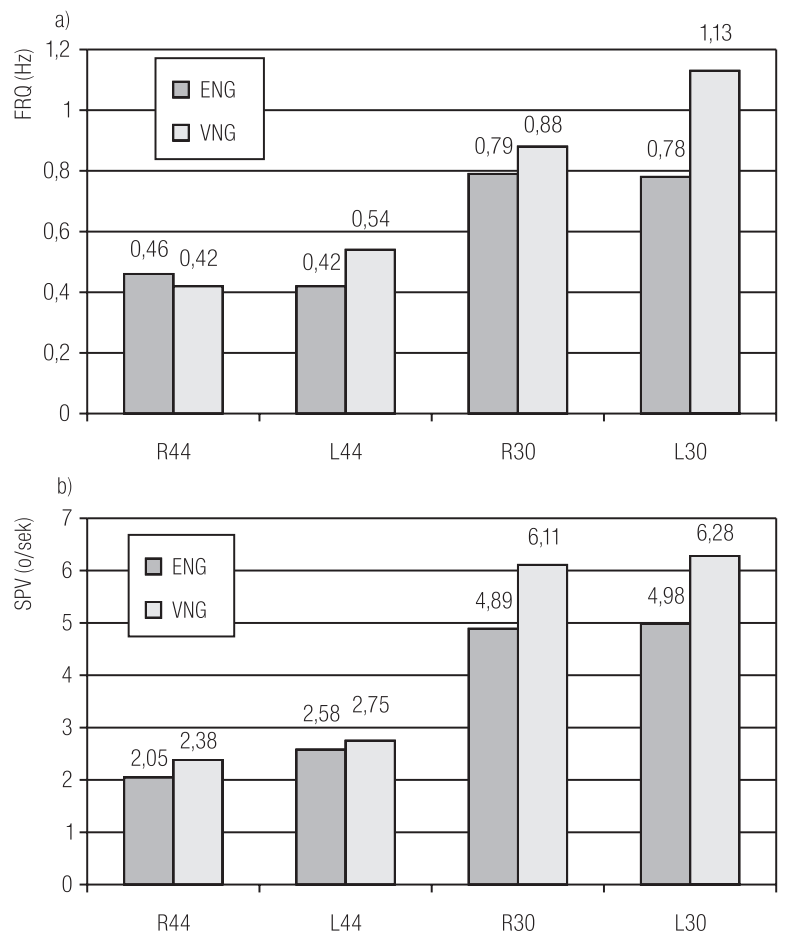

Fig. 3. Compared (ENG vs. VNG) parameters of nystagmus in central vertigo patients (group I): a) mean values of frequency of induced nystagmus (FRQ), b) mean values of slow phase angular velocity (SPV)

found in SPV measurement in any of the compared stimulations for the right and the left ear $(p>0.05)$. However, it was observed that when ENG method was used, generally the mean values of SPV were lower than when VNG method was applied (Figure 4b).

In group III (mixed causes of vertigo) the values of DP were found both in ENG and VNG to exceed the normal limit: 10 times (40\%) simultaneously in VNG and ENG, 6 times $(24 \%)$ only in ENG and in 5 patients $(20 \%)$ in VNG examination. However, $\mathrm{CP}$ exceeding the normal limit was observed in all investigated patients both in VNG and ENG examinations.

The mean of VE was $13.45^{\circ} / \mathrm{s} \pm 8.31$ : 10 times $(40 \%)$ on the right side, the mean value $14.44^{\circ} / \mathrm{s} \pm 7.44$ and 15 times $(60 \%)$ on the left side, the mean value $12.79 \%$ s \pm 9.03 . Evaluating mean of FRQ, it was found that in 2 cases it was higher in VNG than in ENG ((R30, L30) and in
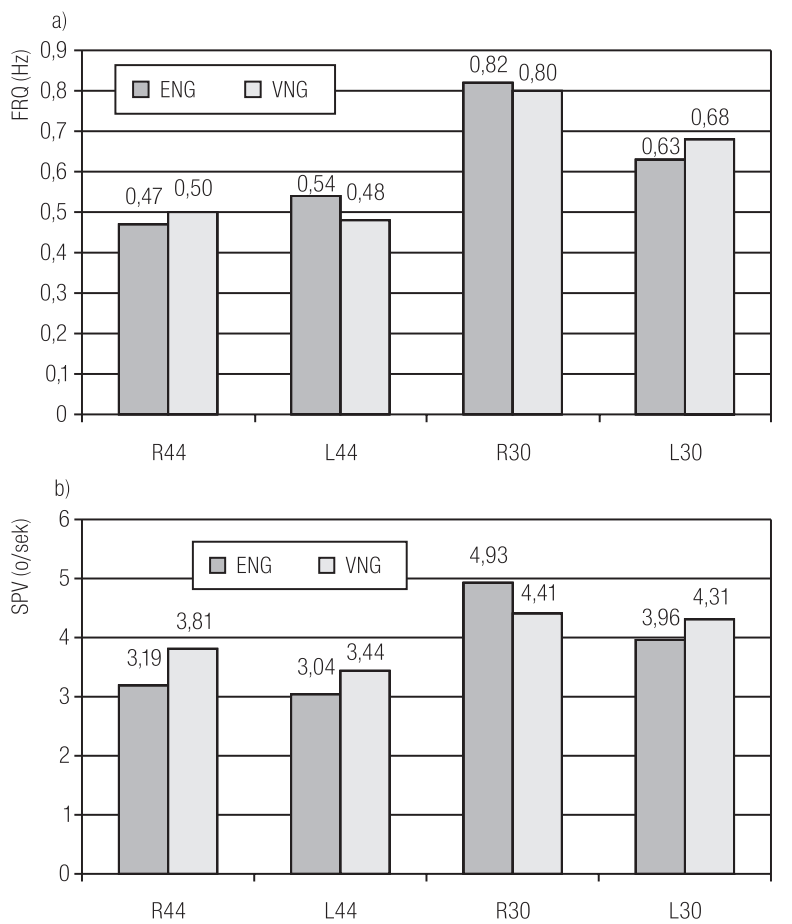

Fig. 4. Compared (ENG vs. VNG) parameters of nystagmus in peripheral vertigo patients (group II): a) mean values of frequency of induced nystagmus (FRQ), b) mean values of slow phase angular velocity (SPV)

both cases the difference was statistically significant (Figure 5a). Also, statistically significant lower values of mean SPV recordings were obtained in ENG vs. VNG method in three cases (Figure 5b).

In the group IV of controls the values of DP were found to exceed the normal range as follows: in 10 cases (40\%) simultaneously in VNG and ENG examinations, in 3 cases (12\%) only in ENG and in 3 cases (12\%) in VNG. CP was absent or did not exceed the normal range.

The mean of $\mathrm{VE}$ was $17.75^{\circ} \mathrm{s} \pm 11.05$ : in 15 subjects $(60 \%)$ on the right side, the mean value $15.98 \% \pm 6.69$ and in 10 subjects $(40 \%)$ on the left side, the mean value $18.85 / \mathrm{s} \pm 13.16$.

Lower values of mean FRQ were observed in ENG than in VNG in all cases, but statistical significance was found only in two cases (Figure 6a). Statistically significant differences were noted in the SPV values (Figure 6b). 

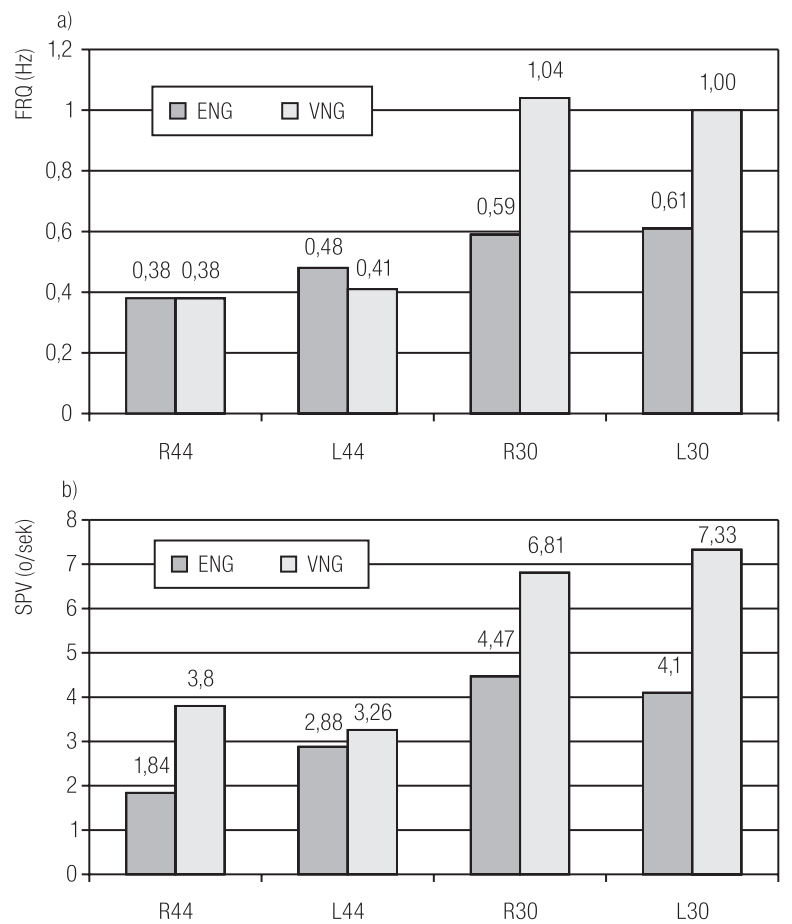

Fig. 5. Compared (ENG vs. VNG) parameters of nystagmus in mixed vertigo patients (group III): a) mean values of frequency of induced nystagmus (FRQ), b) mean values of slow phase angular velocity (SPV)

Mean SPV appeared to be significantly lower in ENG than in $\mathrm{VNG}(\mathrm{p}<0.001)$.

In all examined groups with vertigo, the results of the measurements of SPV showed high differentiation as seen by very high variation coefficients many times exceeding $100 \%$. The variability of SPV appeared to be high in the control group, although it was significantly lower than in the study groups. No cases of spontaneous nystagmus were registered in all material.

\section{DISCUSSION}

Vertigo is not a disease but a symptom of disease, and belongs to one of the most common symptoms (as common as back pain or headache) that will prompt a person to seek medical care. The overall incidence reaches $40 \%$ in patients older than $50[9,10,13]$ and the resulting falls are leading
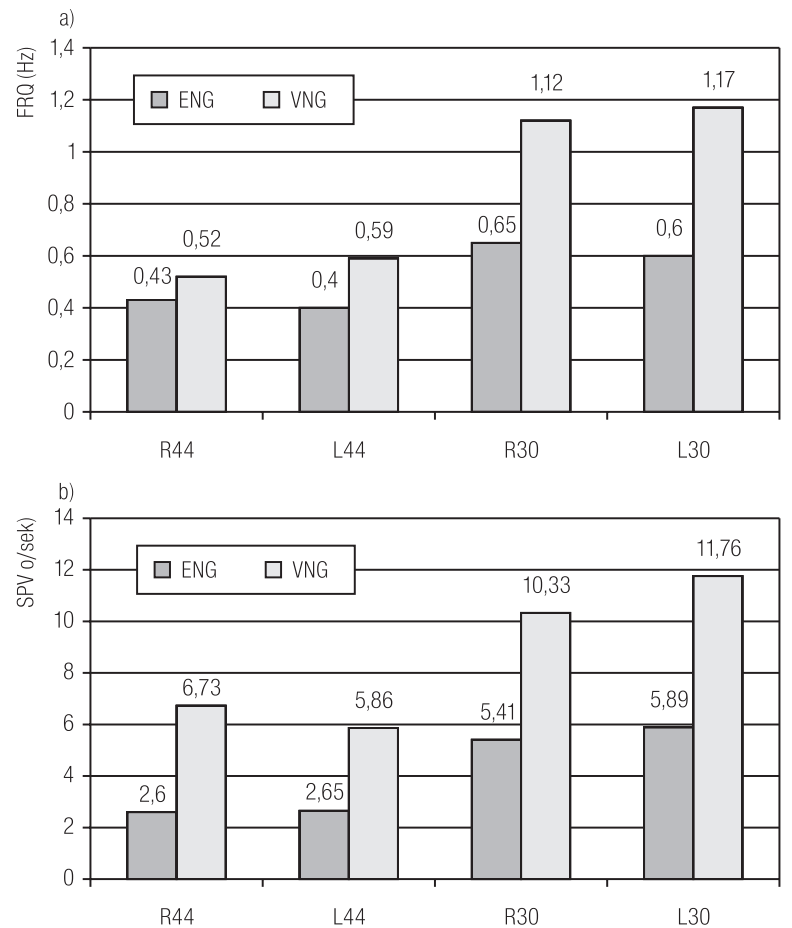

Fig. 6. Compared (ENG vs. VNG) parameters of nystagmus in healthy subjects (group IV): a) mean values of frequency of induced nystagmus (FRQ), b) mean values of slow phase angular velocity (SPV)

cause of death from injury in people older than 65 [9]. The term may mean different things to different people but usually implies that there is a sensation of motion either of the person or the environment, often perceived as if the room is spinning around. Patients often describe difficulty with driving, walking in large open spaces or crowded environments such as supermarkets. A number of conditions can produce vertigo with characteristic features that allow the clinician to suspect an etiological diagnosis. The most frequent reason are the lesions of vestibular system both peripheral (semicircular canals, otoliths, vestibular nerve in the inner ear) and central (vestibular nuclei in brain stem, cerebellum, brain). Hence, vertigo is generally produced when injury occurs to one vestibular apparatus while the other remains intact or when there is asymmetric involvement. A classical example is that which occurs in patients with vestibular neuritis (due to the vestibular nerve inflammation). Other 
examples of peripheral vestibular dysfunctions are: benign paroxysmal positioning vertigo BPPV (seen in patients following head trauma or idiopathic origin seen in the elderly), Ménière's disease (endolymphatic hydrops), acoustic neuroma, barotrauma, cervical vertigo (due to osteoarthritis). The causes of central vestibular disorders include brain concussion, tumours of central nervous system, vertebrobasilar insufficiency, multiple sclerosis, epilepsy, presbyastasis. As mentioned earlier, vertigo may also be associated with some occupational diseases (e.g., kinetosis, vibration syndrome, barotrauma, decompression sickness) and occupational poisonings, mainly by solvents and their mixtures [3,4]. The symptom of vertigo may also appear on a general medical basis in such diseases like arterial hypertension, diabetes mellitus, hypo- and hyperthyreosis, arteriosclerosis, as well as from non-vestibular causes other than inner ear dysfunction, e.g., visual disturbances (reduced vision due to cataracts) [13,19]. Several methods are available for objective diagnosing of vertigo, each with its own advantages and disadvantages.

In this study, two modern methods, namely ENG and VNG with caloric testing, were used to compare their relative value. The results of assessment of the caloric test induced nystagmus in three groups of patients with different causes of vertigo confirmed the clinical significance of canal paresis $(\mathrm{CP})$ known also as unilateral weakness, which is indicative of a peripheral vestibular lesion that involves the nerve or end-organ on the side of the weakness (loss of excitability) [8,13,20]; CP was found in all patients of group II, both in ENG and VNG, with diagnosed vestibular neuritis, otic barotrauma or kinetosis. Only in 3 cases it was associated with directional preponderance (DP). On the other hand, none of the patients of group I with central origin disorders showed CP in VNG, while 5 persons showed it in ENG; in the majority there prevailed DP defined as a measure of the relative strength of rightbeating versus leftbeating nystagmus provoked by caloric stimulation, thought to be rather an indicator of central vestibular abnormality and sometimes occurring in healthy individuals $[8,20]$ (in our study in 10 cases both in ENG and VNG, and 3 per each method separately). As anticipated, the patients with vertigo of mixed origin (group III) presented usually the appearance of DP plus $\mathrm{CP}$.

As to the remaining examined parameters of postcaloric nystagmus, i.e., frequency (FRQ) and slow phase velocity (SPV), there were no essential differences between ENG vs. VNG, except for higher values in VNG in controls (group IV) and patients with mixed vertigo (group III). It should be emphasized that SPV, i.e., measurement of the nystagmus intensity, supplies to the examiner an important data to correctly interpret the findings in terms of CP/DP as well as of vestibular excitability (VE) evaluated as normal symmetrical or abnormal (partial or total) loss of VE. Unfortunately, the ENG examination has some limitations: only $44^{\circ} \mathrm{C}$ and $30^{\circ} \mathrm{C}$ recording of the eyeball movements is feasible in the vertical and horizontal plane, respectively $[4,14-18]$. Hence, VNG use is preferable and the ENG should be used only when $V N G$ is technically difficult [8]. In particular, the caloric stimulation of the vestibular system, which enables assessment of the lateral semicircular canal is considered as the most valuable technique for the documentation of the site of vestibular disorder $[8,12,20,21]$. However, many abnormalities, particularly of central origin, remain non-localizable; therefore, the clinical history and otologic examination of the patient with vertigo are vital in formulating the diagnosis and treatment plan.

\section{CONCLUSIONS}

The data presented prove that ENG and VNG basically do not differ. However, our findings seem to indicate that VNG is more useful and reliable in diagnosing of vertigo due to peripheral vestibular lesion (detection of $\mathrm{CP}$ ), whereas ENG turns out to be useful in identification of vertigo resulting from central or mixed vestibular pathology. 


\section{REFERENCES}

1. Józefowicz-Korczyńska M, Łukomski M, Pajor A. Electronystagmographic evaluation of the vestibular organ condition in patients with tinnitus and cervical spine degeneration. Otolaryngol Pol 2004;58(2):349-53 [in Polish].

2. Olszewski J, Repetowski M. Clinical analysis of cervical vertigo patients in the own material. Otolaryngol Pol 2008;62(3): 283-7 [in Polish].

3. Sułkowski WJ, Kowalska S, Matyja W, Guzek W, Szymczak W, Kostrzewski P. Effects of occupational exposure to a mixture of solvents on the inner ear: a field study. Int J Occup Med Environ Health 2002;15:247-56.

4. Obrębowski A, ed. Standards in diagnosis and treatment of vertigo. Warszawa: Oinpharma; 2010 [in Polish].

5. Furman JM, Whitney SL. Central causes of dizziness. Phys Ther 2000;80(2):179-87.

6. Labuguen RH. Initial evaluation of vertigo. Am Fam Physic 2006;73(2):244-51.

7. Lempert T, Neuhauser H. Epidemiology of vertigo, migraine and vestibular migraine. J Neurol 2009;256:333-8.

8. British Society of Audiology. Recommended procedure. The caloric test. London: BSA; 2010.

9. Yin M, Ishikawa K, Wong H, Shibata Y. A clinical epidemiological study in 2169 patients with vertigo. Auris Nasus Larynx 2009;36:30-5.

10. Neuhauser HK, Radtke A, Von Brevern M, Lezius F, Feldmann M, Lempert T. Burden of dizziness and vertigo in the community. Arch Intern Med 2008;168:2118-24.

11. Gawron W, Pośpiech L, Orendorz-Frączkowska K, Noczyńska A. Evaluation of the changes in the auditory organ and vestibular organ in patients with diabetes type 1. Otorynolaryngol 2002;1(2):119-23 [in Polish].
12. Janczewski G. Vertigo. Warszawa: Solvay Pharma; 2000 [in Polish].

13. Pierchała K. Cause analysis of vertigo and balance disorders. Bibl Prosper Ménière 1998;2(1):9-21 [in Polish].

14. Olszewski J, Pietkiewicz P, Miłoński J, Bielińska M. The use of VHIT (Videonystagmography Head Impulse Test) in diagnostics of semicircular canals injuries. Otolaryng Pol 2010;64(7):32-5 [in Polish].

15. Kenig D, Kantor I, Jurkiewicz D. Balance system evaluation in multiple sclerosis patients on the basis of videonystagmography qualitative analysis. Pol Merk Lek 2005;19(111):301-3 [in Polish].

16. Pepaś R, Pietkiewicz P. Olszewski J. Comparative analysis of nystagmus caloric test results with the use of ENG and VNG in healthy subjects. Aktualn Neurol 2010;10(1):51-4 [in Polish].

17. Olszewski J, Pietkiewicz P, Bielińska M. Concurrent ENG and VNG recording in healthy people. In: Niedzielska G, editor. 6th Conference of Audiology and Phoniatric Section of Polish Society of Otorhinolaryngologists - Head and Neck Surgeons, 2009 Jun 18-20; Lublin, Poland [in Polish].

18. Lightfoot GR. The origin of order effects in the results of the bi-thermal caloric test. Int J Audiol 2004;43(5):276-82.

19. Janczewski G, Latkowski B, eds. Otoneurology. Vol. 1-2. Warszawa: Bel Corp; 1998 [in Polish].

20. Jacobson GP, Newman CW, Kartush JM, eds. Handbook of balance function testing. St. Louis: (MI): Mosby Year Book; 1993.

21. Zapala DA, Olsholt KF, Lundy LB. A comparison of water and air caloric responses and their ability to distinguish between patients with normal and impaired ears. Ear Hear 2008;29: $585-600$.

This work is available in Open Access model and licensed under a Creative Commons Attribution-NonCommercial 3.0 Poland License - http://creativecommons.org/ licenses/by-nc/3.0/pl/deed.en. 